\title{
Effects of Sorptive Tendency of Shale on Borehole
}

\section{Stability}

\author{
Vahid Dokhani ${ }^{1}$ and Mengjiao $\mathrm{Yu}^{2}$ \\ 1. YU Technologies, Inc., Tulsa, OK 74133, USA \\ 2. McDougall School of Petroleum Engineering, University of Tulsa, Tulsa, OK 74104, USA
}

\begin{abstract}
Interactions between aqueous drilling fluids and clay minerals have been identified as an important factor in wellbore instability of shale formations. Current wellbore stability models consider the interactions between aqueous drilling fluids and pore fluid but the interactions with shale matrix are neglected. This study provides a realistic method to incorporate the interaction mechanism into wellbore stability analysis through laboratory experiment and mathematical modeling. The adsorption isotherms of two shale rocks, Catoosa Shale and Mancos Shale are obtained. The adsorption isotherms of the selected shales are compared with those of other shale types in the literature. This study shows that the adsorption theory can be used to generalize wellbore stability problem in order to consider the case of non-ideal drilling fluids. Furthermore, the adsorption model can be combined with empirical correlations to update the compressive strength of shale under downhole conditions. Accordingly, a chemo-poro-elastic wellbore stability simulator is developed to explore the stability of transversely isotropic shale formations. The coupled transport equations are solved using an implicit finite difference method. The results of this study indicate that the range of safe mud weight reduces due to the moisture adsorption phenomenon.
\end{abstract}

Key words: Wellbore stability, shale, sorption isotherm, moisture content, pore pressure, rock failure.

\section{Introduction}

Shale rocks are often regarded as weak rocks in terms of compressive and tensile strength. It is known that presence of bedding planes and lamination imparts anisotropy to mechanical properties of rocks. The effect of bedding plane on rock failure has long been recognized [1-3]. Drilling through shale formations is often associated with borehole instability problems. York et al. (2009) reported that the wellbore instability issues in a well with $20,000 \mathrm{ft}$ measured depth could at least cost 2.5 million dollars [4].

It is reported that one third of NPT (non-productive time) of drilling operations is spent on wellbore problems, of which a major portion is attributed to the wellbore instability issues [5]. Hydration of clay minerals is recognized to be one of the important interaction processes between shale and drilling fluid

Corresponding author: Vahid Dokhani, technology specialist, research fields: wellbore stability, drilling fluid, wellbore hydraulics, cementing, and well control. during drilling process, which often leads to various operational problems such as shale swelling, stuck pipe, reduction of rate of penetration $[6,7]$. Usually two kinds of clay swelling is realized, namely, the interacrystalline swelling due to the hydration of exchangeable cations and osmotic swelling which occurs due to a large difference between ion concentration (or water activity) of shale and aqueous fluids [8-10].

There are two main approaches to the investigation of interactions between shale and aqueous fluid. The first approach considers the forces acting on the clay and electrolyte system. Theoretical models assume that the charged clay surface along with the counter-ions in the pore water form an electrical or diffuse double layer. The double layer encompasses a layer of sorbed counter ions (and associated hydration water) and a diffuse layer. The first layer (immobile layer) is strongly bounded to the surface, which is referred as the Stern layer. The region adjacent to the Stern layer is 
called the diffuse layer in which diffusion of ions and water is relatively free [11-14]. However, the porous medium is idealized as a system of parallel clay platelets where the electrical charges are uniformly distributed, and not all of the required parameters can be obtained experimentally. The other approach attempts to model the movement of fluid and ions in terms of macroscopic driving forces. This method is favored since it can be verified by experiments and can be extended for field applications. Due to ion exclusion characteristic of shale, it is shown that the membrane efficiency of shale can be determined from the ratio of hydraulic gradient and the theoretical osmotic pressure gradient under zero volumetric flux $[6,15]$. Once the membrane efficiency is determined, the chemical osmotic coefficient can be expressed as the product of hydraulic conductivity and membrane efficiency. The magnitude of chemical potential of water within shale is usually approximated in terms of the solute concentration of the pore fluid [16-18]. Nevertheless, this assumption does not include interactions between the pore fluid and the rock matrix and is not valid for non-ideal solutions. In addition, sensitivity analysis based on the current state of wellbore stability theory showed that the effect of chemical imbalance and membrane efficiency on mud weight is only $13 \%$ and $1 \%$, respectively [19].

The above discussion is a motivation of this paper to develop a unified model that considers the interaction between shale and aqueous fluid through experimental observation and mathematical modeling. The formulation also aims to remove the ideal solution assumption. It is the purpose of this paper to derive such explanations using the sorption theory.

\section{Sorption Isotherms}

Sorption isotherm is a useful approach to describe the hydration process of clay minerals [20, 21]. Sorption isotherm describes the adsorbed amount of water per gram of dry sample as a function of relative pressure or relative humidity at room temperature and pressure. According to the literature, the type curves of sorption isotherms can be identified based on porous structure of the surface and multilayer sorption phenomena as shown in Fig. 1 [22]. To describe the sorption process between aqueous fluids and shale rocks, it is essential to briefly review the sorption behavior of water vapor on clay minerals.

\subsection{Sorption Isotherms of Clays Minerals}

The sorption of water by relatively pure clay minerals has long been an interest topic of researchers to describe the physical characteristics of different clay types [8, 20, 23-26]. The authors concluded that BET (Brunauer-Emmett-Teller) isotherms (Type curves II and III in Fig. 1) can predict the sorption behavior of various clay minerals. However, it is stated that the GAB (Guggenheim, Anderson and De Boer model) can be used to describe the sorption path of clay minerals $[27,28]$. Experimental investigations showed a strong correlation between CEC (cation exchange capacity) of clay and adsorbed amount of water [29, 30].
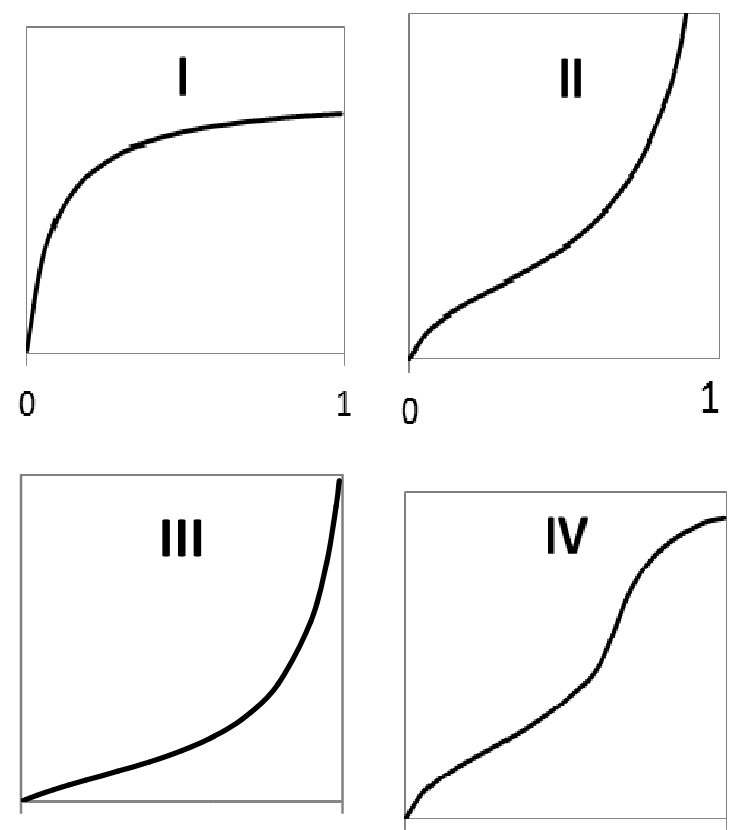

0 1 1

Fig. 1 Gas sorption isotherms: (I) small pore size and uni-molecular adsorption, (II, III) wide range of pore size and multilayer adsorption, and (IV) two surface layer adsorption [22]. 
It is reported that the CEC of various clay minerals is linearly related to the specific surface area of clay $[25$, 29, 30]. Salles et al. (2009) proposed a relationship to determine specific surface area of a clay material from water sorption isotherm. Using $\mathrm{CEC}$ to scale the sorption isotherms of various clays is also suggested $[25,31]$. By analyzing different data sets of sorption tests, Woordruff and Revil (2011) showed that a plot of relative humidity versus mass of sorbed water per meq (a unit of cation exchange capacity measurement) for various clays can be collapsed into a unified isotherm if relative humidity is less than $60 \%$ [25].

\subsection{Sorption Isotherms of Shale Rocks}

The sorptive tendency of shale rocks toward aqueous solutions has been investigated by several researchers [21, 32, 33]. Chenevert [21] observed that the sorption isotherms of selected shale types are to be hysteretic. Tandanand [32] reported that both compressive strength and tangent modulus of the Illinois shale reduce linearly with increase in moisture content. Fonseca [33] identified a linear isotherm correlation for a sample of Kimmeridge shale. However, we investigated the experimental results of Fonseca [33] and found that the mismatch parameter of the correlation can be improved using an exponential relationship. Furthermore, it can be realized that the isotherm of Kimmeridge shale is comparable to the isotherms of type II or III. Krushin [31] stated that the value of CEC as a scaling parameter can be used to unify the sorption isotherms of different shale types. The author suggested inferring the value of CEC of shale by matching its sorption isotherm with the pre-established sorption trend-line. Krushin [34] proposed a compaction model based on the sorption potential and CEC of shale rock to predict pore pressure in shale formations.

\subsection{Mathematical Models of Sorption Isotherms}

A common isotherm model describing the sorption of a gas on reactive surfaces is the BET model. The model assumes arbitrary number of adsorbate molecules can be attached at each site without any interaction between the layers $[22,35]$. The BET equation is expressed as:

$$
w=\frac{q_{m} a_{w} c}{\left(1-a_{w}\right)\left(1+(c-1) a_{w}\right)}
$$

where $w$ is the moisture content of the material (gram of water per 100 gram of solid), $q_{m}$ represents the monolayer moisture content (amount of adsorbate that completes a monolayer coverage of the surface), often reported as gram of water per 100 gram of solid, $a_{w}$ is water activity, and $c$ is an energy constant related to the difference in the heat of adsorption of the first layer and the other layers $(\mathrm{J} / \mathrm{mole})$. The assumptions of the theory have been questioned by various investigators [24, 35, 36]. Anderson [36] showed that the BET model overestimates the sorbed amount to the solid when relative pressure is greater than 0.4. Foo and Hameed [37] showed that the BET model can be used with relative pressures ranging from 0.05 to 0.3 . Woodruff and Revil [25] showed that using the BET model, the adsorption isotherm of various clays can be unified into a single isotherm except for relative humidity greater than 0.6. Comparing data sets of sorption isotherm taken from the literature, Dokhani et al. [38] stated that the BET model fails to reproduce the correct sorption path for wide range of water activity.

The GAB is a modification of the Langmuir and BET theories of sorption isotherms, which assumes that the state of adsorbate molecules in the first layer is different from the subsequent layers. The isotherm model has a third constant, $k$, which is related to the difference between the heat of sorption in the multilayer system and the heat of condensation [36]. The GAB model is expressed as follows:

$$
w=\frac{q_{m} k a_{w} c}{\left(1-k a_{w}\right)\left(1+(c-1) k a_{w}\right)}
$$

when $k$ is equal to 1 , the above model reduces to the BET equation. It is shown that the GAB model is 
applicable to a wide range of water activity from 0.1 to 0.9 for different clay types or shale rocks $[27,28,38]$.

\section{Experimental Method}

This section describes the experimental procedure to obtain the adsorption isotherms of two rock types, namely Mancos shale and Catoosa shale. The technique is based on direct control of the humidity and temperature over shale samples. The Catoosa shale and Mancos shale, which were provided by National Oilwell Varco, were preserved in aluminum foil and wax before any exposure. Several plugs were obtained from the bulk shale cores. Then, the samples were prepared by grinding shale plugs to 8-10 mesh size and dried for about 20 hours in an oven at a temperature of $220^{\circ} \mathrm{F}$. The samples were weighted before and after drying to determine the in-situ moisture content of the sample. The in-situ moisture content of Mancos Shale and Catoosa shale are obtained as $1.3 \%$ and $1.1 \%$, respectively. A solution of known water activity was prepared to control the humidity over the shale samples. Here, the aqueous solution was prepared using calcium chloride or sodium chloride since the value of water activity as a function of salt concentration is available [39]. The samples were confined within a desiccator, which is a controlled humidity environment. The temperature of the room during the test was kept constant. The final weight of each sample was measured after a month to ensure equilibrium conditions between shale samples and the humidity of the desiccator.

\section{Experimental Results}

A comparison between our experimental results for the given shale rocks and the data set derived from published studies is illustrated in Fig. 2. Chenevert (1970) studied adsorption isotherms for shale A, D and C [21]. Chenevert and Osisanya [40] investigated adsorption isotherm of Midway shale and Wellington shale. Fonseca (1998) obtained the adsorption isotherm of Kimmeridge shale [33]. The results indicate that the adsorption potential of Mancos Shale is the lowest among the selected shale types.

As suggested before, the GAB model can be used to reproduce the sorption path of different shale formations. Here, the sorptive properties of four selected shale formations are presented in Table 1.

The sorption model outlined here has a practical application for real-time prediction of rock compressive strength to be coupled with wellbore stability simulators. The output of the model is the moisture content, which is an important parameter to update the UCS (uniaxial compressive strength) of the rock. It is shown that increase in the moisture content of shale has a negative effect on its compressive strength, as noted by various investigators [21, 43-46]. The presented correlations share a common theme in which uniaxial compressive strength reduces exponentially as the moisture content increases (Table 2). It should be pointed out that the range of uniaxial compressive strength at dry conditions is an

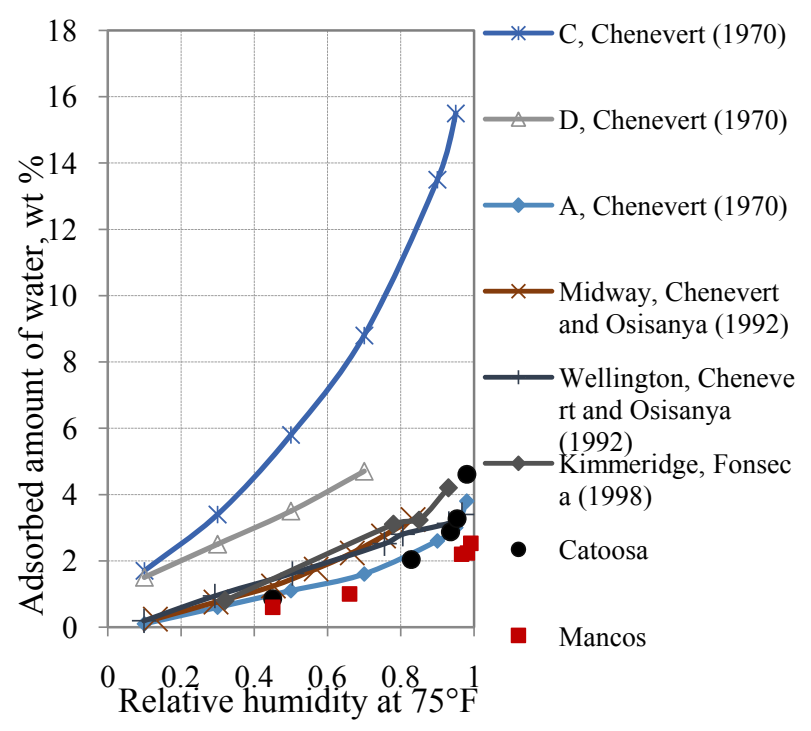

Fig. 2 Sorption isotherms of several shale formations.

Table 1 Sorptive properties of the selected shale types.

\begin{tabular}{lllll}
\hline Shale & $\mathrm{q}_{\mathrm{m}}$ & $\mathrm{k}$ & $\mathrm{c}$ & $\mathrm{R}^{2}$ \\
\hline Mancos & 0.003 & 0.885 & 10 & 0.957 \\
Catoosa & 0.004 & 0.854 & 10 & 0.992 \\
Midway & 0.01 & 0.864 & 6 & 0.978 \\
Shale C & 0.041 & 0.800 & 5 & 0.991 \\
\hline
\end{tabular}


Table 2 Empirical correlations of uniaxial compressive strength of shale in terms of moisture content.

\begin{tabular}{llll}
\hline UCS Model & $\mathrm{C}_{0}{ }^{\text {dry }}, \mathrm{MPa}$ & Clay content, \% & Reference \\
\hline$C_{0}{ }^{d r y} e^{-0.034 w}$ & $182-196$ & NA & {$[43]$} \\
$C_{0}{ }^{d r y} e^{-0.083 w}$ & $30-40$ & $>40 \%$ & {$[45]$} \\
$C_{0}{ }^{d r y} e^{-0.443 w}$ & $80-100$ & NA & {$[44]$} \\
$C_{0}{ }^{d r y} e^{-0.444 w}$ & $80-100$ & $>60 \%$ & {$[46]$} \\
\hline
\end{tabular}

important parameter for selection of the appropriate correlation. It is also noted that UCS can be related to physical properties of shale, such as porosity or elastic moduli $[47,48]$.

\section{Mathematical Modeling}

\subsection{A Diffusion-Sorption Model}

The chemical imbalance between the drilling fluid and shale formation is usually expressed in terms of the solute concentration of the aqueous fluid [16, 17]. However, there are various types of chemical reactions that affect the concentration of solute during transport in porous media, such as cation exchange and sorption phenomena [49]. The available mathematical models that describe wellbore stability in shale formations have several limitations; the interaction between solvent and pore space is neglected in the transport equations, the drilling fluid is assumed to be an ideal solution. Although the models assume that solute is retarded from the pore space through a so-called "membrane efficiency", measurement of sorbed mass of solute is a difficult task in a dynamic system. Besides, the influence of solute transport on physical properties of the rock mass is ambiguous.

There were few attempts in the literature to develop the transport equations based on solvent rather than solute. Yew et al. [50] assumed that diffusion of water is only a function of moisture content of the rock. Hence, the effect of chemical potential is ignored in the constitutive equations. But, the authors did not discuss how to describe the moisture content at the wellbore wall. Huang et al. [51] developed a theoretical model that is claimed to be applicable for non-ideal solutions. However, water activity is approximated as a function of the mole fraction of water in the pore space, which is an ideal-solution assumption. The authors mainly considered the interactions between the pore fluid and the drilling fluid, while the interactions of aqueous fluid with the rock matrix are neglected [51]. The above approaches do not address the effect of aqueous fluid on the physical properties of shale.

The above arguments suggest that the continuity equation should be established based on solvent. Here, the geometry of the problem is a cylindrical shale rock surrounding a wellbore, where the fluid flow and moisture transport occur radially due to the imposed initial and boundary conditions. The following analysis assumes radial symmetry around the borehole. For a binary solution, under isothermal conditions, the constitutive transport equations can be written as follows [52]:

$$
\begin{aligned}
& J_{w}=-L_{I} \frac{\partial P}{\partial r}-L_{I I} R T \frac{\partial \operatorname{Lna_{w}}}{\partial r} \\
& J_{v}=-K_{I} \frac{\partial P}{\partial r}-K_{I I} R T \frac{\partial \operatorname{Ln} a_{w}}{\partial r}
\end{aligned}
$$

where $J_{w}$ is the molar flux of solvent and $J_{v}$ is the volumetric solution flux. In the above formulatiom, $L_{I}$ and $L_{I I}$ are related to the advective and diffusive coefficients of moisture in shale matrix. In addition, $K_{I}$ and $K_{I I}$ represent the hydraulic coefficient and chemical potential coefficient, respectively. The moisture content is defined as:

$$
w(r, t)=\frac{m(r, t)-m_{d}}{m_{d}}
$$

where $m$ and $m_{d}$ represent the instantaneous weight of exposed shale and dry shale, respectively. Neglecting the advective flux of water, the continuity equation can be written using Eqs. (3) and (5):

$$
\frac{\partial w}{\partial t}=D_{w}^{e f f}\left(\frac{\partial^{2} L n a_{w}}{\partial r^{2}}+\frac{1}{r} \frac{\partial L n a_{w}}{\partial r}\right)
$$

where $D_{w}^{e f f}$ is the moisture diffusivity coefficient defined as:

$$
D_{w}^{e f f}=\frac{L_{I I} R T}{\rho_{s}}
$$

where $\rho_{s}$ is the density of dry shale, $R$ is the universal gas constant, and $T$ is the absolute temperature. It is 
noted that Eq. (6) cannot be solved directly, since it has two unknowns, i.e., water activity and moisture content. Using the GAB model to describe the sorption process, the chain rule suggests:

$$
\frac{\partial w}{\partial t}=\frac{\partial w}{\partial a_{w}} \frac{\partial a_{w}}{\partial t}=f\left(a_{w}\right) \frac{\partial a_{w}}{\partial t}
$$

where $f\left(a_{w}\right)$ is obtained by differentiating the sorption model (i.e., the GAB model) with respect to $a_{\mathrm{w}}$. It is shown that the chemical osmosis coefficient can be approximated in terms of parameters, which can be found in the literature [50]:

$$
K_{I I} \approx D_{w}^{\text {eff }} \overline{V_{w}}
$$

Then, the continuity equation for the bulk solution in a cylindrical coordinate system is written as:

$$
\frac{\partial(\rho \phi)}{\partial t}=-\frac{\partial\left(\rho J_{v}\right)}{\partial r}-\frac{\left(\rho J_{v}\right)}{r}
$$

For a slightly compressible fluid, substituting Eq. (4) into Eq. (10) and neglecting the higher order differential terms yields:

$$
\begin{gathered}
\frac{\partial p}{\partial t}=\frac{K_{I}}{\phi c_{t}}\left(\frac{\partial^{2} p}{\partial r^{2}}+\frac{1}{r} \frac{\partial p}{\partial r}\right) \\
+\frac{K_{I I} R T}{\phi c_{t}}\left(\frac{\partial^{2} L n a_{w}}{\partial r^{2}}+\frac{1}{r} \frac{\partial L n a_{w}}{\partial r}\right)
\end{gathered}
$$

where $\phi$ is the porosity and $c_{t}$ is the total compressibility. For an unbounded shale formation, the system of equations, i.e. Eqs. (6) and (11), is subjected to the following initial and boundary conditions:

$$
\begin{gathered}
a_{w}\left(r_{w}, t>0\right)=a_{d f} \\
a_{w}(r, 0)=a_{s h} \\
a_{w}(r \rightarrow \infty, t)=a_{s h} \\
p\left(r_{w}, t>0\right)=P_{w b} \\
p(r, 0)=P_{o} \\
p(r \rightarrow \infty, t)=P_{o}
\end{gathered}
$$

where $a_{s h}$ and $a_{d f}$ are the in-situ water activity of shale and water activity of the drilling fluid, respectively. Also, $P_{o}$ and $P_{w b}$ represent the in-situ pore pressure and wellbore pressure, respectively. The solution procedure to obtain pore pressure and moisture content around the borehole is explained in Appendix A.

\subsection{Wellbore Stability Modeling}

There are numerous publications about wellbore stability analysis in the literature. However, based on the subject of study, proposed models can be classified as: poro-elastic models [53], chemo-poro-elastic [33], thermo-poro-elastic [54], thermo-chemo-poro-elastic $[18,55]$. Wellbore stability models for other applications such as transversely isotropic medium [56], dual porosity-dual permeability medium [57], and coupling with time-dependent effects of mud loss [58], are also investigated in the past.

To obtain the stress distribution around the borehole, the problem is divided into two sub-problems: a mechanical problem and a hydraulic problem. The general solution is obtained by superposition of the solutions of the two parts. The solution of the mechanical problem is described elsewhere [53, 54]. Here, we only describe the procedure to obtain the fluid-induced stresses assuming that shale formation is homogenous, unbounded, transversely isotropic and under isothermal conditions. Assuming axial symmetry around the borehole, the equilibrium equation yields:

$$
\frac{\partial \sigma_{r r}}{\partial r}+\frac{\sigma_{r r}-\sigma_{\theta \theta}}{r}=0
$$

where $\sigma_{r r}$ and $\sigma_{\theta \theta}$ represent the radial and hoop stress, respectively. Under plane strain condition, it is assumed that the plane of isotropy is perpendicular to the wellbore axis (Fig. 3). The relationship between the strain and displacement in cylindrical coordinates is written as:

$$
\begin{gathered}
\varepsilon_{r r}=\frac{\partial u_{r}}{\partial r} \\
\varepsilon_{\theta \theta}=\frac{u_{r}}{r}
\end{gathered}
$$

where $u_{r}$ is the displacement in the radial direction. The constitutive equation of a transversely isotropic medium is written as follows: 


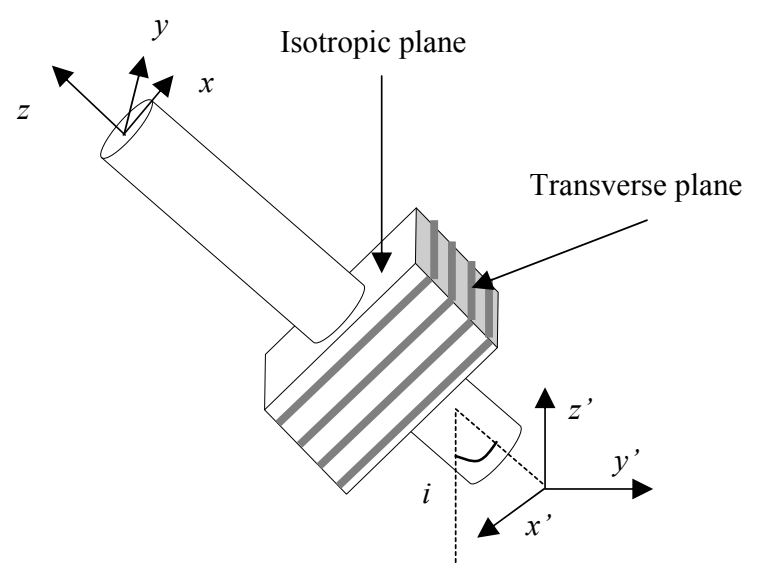

Fig. 3 Schematic of an inclined wellbore in a transversely isotropic formation.

$$
\begin{aligned}
& \sigma_{r r}=M_{11} \varepsilon_{r r}+M_{12} \varepsilon_{\theta \theta}+M_{13} \varepsilon_{z z}+\alpha p \\
& \sigma_{\theta \theta}=M_{12} \varepsilon_{r r}+M_{11} \varepsilon_{\theta \theta}+M_{13} \varepsilon_{z z}+\alpha p \\
& \sigma_{z z}=M_{13} \varepsilon_{r r}+M_{13} \varepsilon_{\theta \theta}+M_{33} \varepsilon_{z z}+\alpha^{\prime} p
\end{aligned}
$$

where:

$$
\begin{aligned}
& M_{11}=\frac{E\left(E^{\prime}-E v^{\prime 2}\right)}{(1+v)\left(E^{\prime}-E^{\prime} v-2 E v^{\prime 2}\right)} \\
& M_{12}=\frac{E\left(E^{\prime} v+E v^{\prime 2}\right)}{(1+v)\left(E^{\prime}-E^{\prime} v-2 E v^{\prime 2}\right)} \\
& M_{13}=\frac{E E^{\prime} v^{\prime}}{\left(E^{\prime}-E^{\prime} v-2 E v^{\prime 2}\right)} \\
& M_{33}=\frac{E^{\prime 2}(1-v)}{\left(E^{\prime}-E^{\prime} v-2 E v^{\prime 2}\right)}
\end{aligned}
$$

where $v, E$ and $\alpha$ are defined in the plane of isotropy and represent drained Poisson's ratio, drained Young's modulus, and the Biot coefficient, respectively. Accordingly $v^{\prime}, E^{\prime}$ and $\alpha^{\prime}$ are drained Poisson's ratio, drained Young's modulus, and the Biot coefficient perpendicular to the plane of isotropy, respectively. The inner boundary condition is the radial stress at the borehole wall, which is the mud pressure. At far field, the radial displacement is assumed to be zero.

Under plain strain assumption, the equilibrium equation can be written in terms of displacement, i.e. substituting Eqs. (15) and (16) into Eqs. (17-19). The resulting formulation is solved using the specified boundary conditions. Hence, the following expressions are obtained as explained in Appendix B:

$$
\begin{gathered}
\sigma_{r r}=\frac{\alpha}{M_{11}} \frac{E}{(1+v)} \frac{1}{r^{2}} \int_{r_{w}}^{r} \Delta p\left(r^{\prime}, t\right) r^{\prime} d r^{\prime}+P_{w b} \frac{r_{w}{ }^{2}}{r^{2}} \\
\sigma_{\theta \theta}=-\frac{\alpha}{M_{11}} \frac{E}{(1+v)}\left(\frac{1}{r^{2}} \int_{r_{w}}^{r} \Delta p\left(r^{\prime}, t\right) r^{\prime} d r^{\prime}-\Delta p(r, t)\right) \\
-P_{w b} \frac{r_{w}{ }^{2}}{r^{2}} \\
\sigma_{z z}=\left(\frac{\alpha v^{\prime} E^{\prime}}{M_{11}(1+v)}+\alpha^{\prime}\left(1-2 v^{\prime}\right)\right) \Delta p(r, t)+\alpha^{\prime}\left(1-2 v^{\prime}\right) P_{o}
\end{gathered}
$$

where:

$$
\Delta p(r, t)=p(r, t)-p(r, 0)=p(r, t)-P_{o}
$$

The transversely isotropic formulation resembles the formulation of isotropic case except different multiplier terms. It can be shown that the above equations, i.e. Eqs. (21-23), are reduced to isotropic formulation once the anisotropic coefficients are replaced with the isotropic material coefficients.

Since the governing transport equations are expressed implicitly as a function of the moisture content, we first proceed with numerical methods to solve for the moisture content and pore pressure as noted earlier. Then, the magnitude of the fluid-induced stresses around the wellbore is evaluated through numerical integration. Afterward, the fluid-induced stress components are superimposed on the mechanical stress components to obtain the overall stress components.

The procedure for a directional wellbore involves transformation of stresses from in-situ stress coordinates to the local coordinates (i.e., wellbore). The transformation laws for second-order tensor are generally written in the index notation:

$$
\sigma_{i j}=l_{i m} \sigma_{m n} l_{n j}^{T}
$$

where $l_{\mathrm{ij}}$ is known as transformation matrices as described elsewhere [59]. 


\section{Modeling Results and Discussion}

The domain of the problem is discretized radially and the coupled equations, i.e. Eqs. (6) and (11), are solved numerically using the finite difference method to obtain pore pressure and moisture content around the borehole. For sensitivity analysis, three shale formations were selected (shale C, Midway and Mancos) to cover wide range of affinity of shale toward aqueous fluid. The adsorption parameters of the above shale rocks were already obtained using the GAB model (Table 1). To investigate the effect of adsorption parameters on pore pressure and moisture content, it is assumed that other physical and transport properties remain constant for all shale types. In addition, it is assumed that all shale types have same in-situ water activity and are exposed to a relatively dilute aqueous drilling fluid. The exposure time is set to 100 hours for all shale types. Table 3 summarizes other input parameters and setup conditions.

\subsection{Effect of Sorption Parameters}

To have a common index for comparison of response of shales toward aqueous solution, it is suggested to plot the change of moisture content as a function of time as shown in Fig. 4. Using the parameters in Table 3 , the time evolution of moisture content at a given radial position (e.g. $r / r_{w}=1.05$ ) is shown for shale $\mathrm{C}$, Midway and Mancos shale. Although Mancos shale exhibits early growth in moisture content, it approached the equilibrium conditions after 100 hours of exposure. On the other hand, the growth rate of moisture content for shale $\mathrm{C}$ surpassed other types and it is far from equilibrium.

The governing equations, i.e. Eqs. (6) and (11), indicate that pore pressure is implicitly correlated with the sorption parameters. Using the adsorption parameters in Table 1, pore pressure profiles in the vicinity of the borehole for the selected shale rocks are plotted in Fig. 5. Although the transport coefficients are assumed to be the same for the selected shales, the magnitude of induced pore pressure due to chemical imbalance can be quite different. It is noted that the peak of induced pore pressure is associated with the largest sorption potential (i.e., shale C). Conversely, Mancos shale, which exhibits less affinity to adsorb water, has the least induced pore pressure. Thus, we can classify the shale rocks based on the estimated magnitude of induced osmotic pressure.

\subsection{Wellbore Failure in a Strike-Slip Stress Regime}

For the sake of wellbore stability analysis, a hypothetical case of a transversely isotropic shale formation is investigated, in which the state of stress at the depth of interest is a strike-slip stress regime, i.e.,

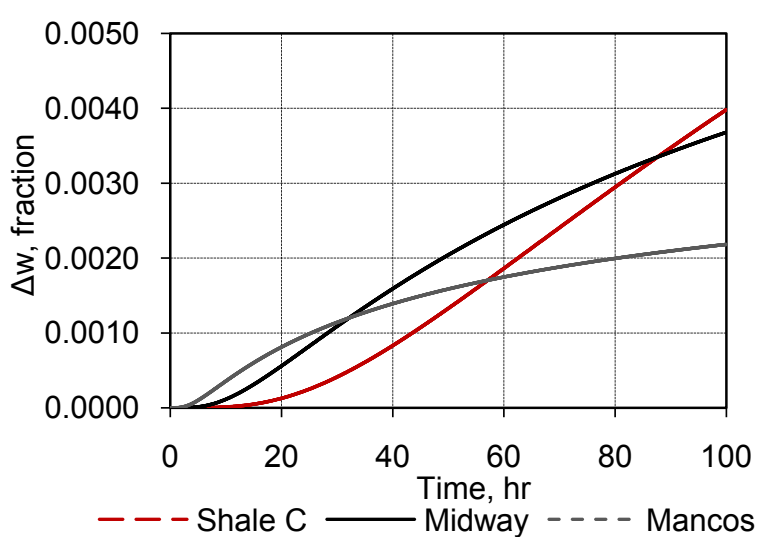

Fig. 4 Simulated time evolution of moisture content for the selected shale formations at $r / r_{w}=1.05$.

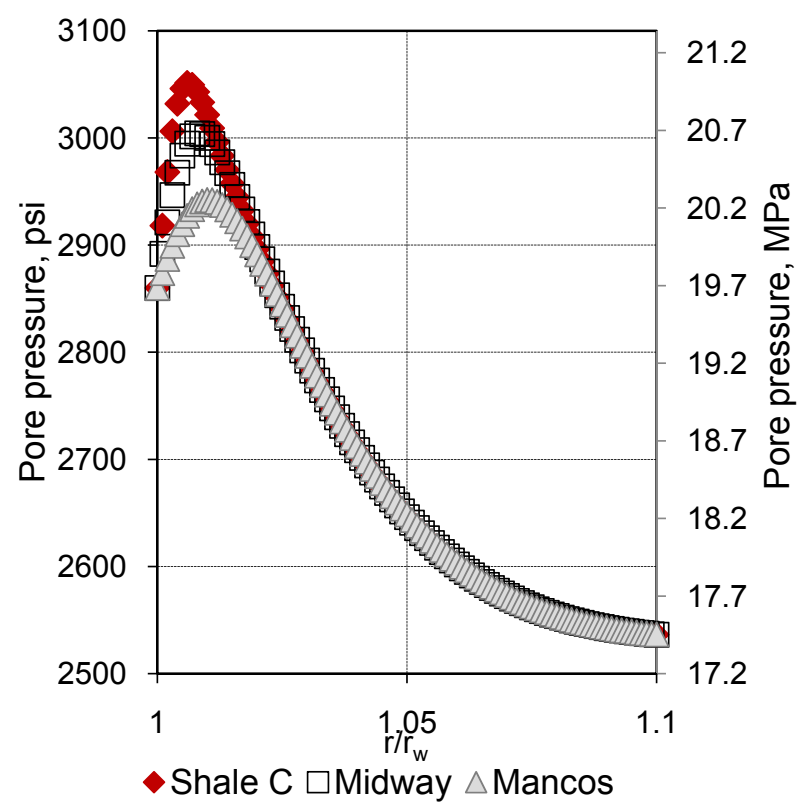

Fig. 5 Comparison of pore pressure distribution around the borehole for the selected shale types. 
the maximum horizontal stress is the maximum principal stress and the minimum horizontal stress is the least principal stress. The necessary input values to conduct a parametric analysis are summarized in Table 3. Among them, there are parameters that can be controlled while drilling, such as mud weight, water activity of the drilling fluid, wellbore azimuth and deviation angle of the borehole.

The sorption characteristics of the hypothetical shale formation are assumed to be those of Midway shale (Table 1). It is assumed that the uniaxial compressive strength of shale follows the empirical correlation proposed by Colback and Wiid (1965) [43]. The conventional compressive failure criterion, namely the Mohr-Coulomb, is investigated to assess the compressive failure of shale formation. To clarify the effect of drilling direction on wellbore stability, the required mud weights are demonstrated in a polar plot. The perimeter scale shows the azimuth from the

Table 3 Input parameters for simulation.

\begin{tabular}{|c|c|}
\hline Parameter & Value \\
\hline Wellbore radius, $\mathrm{ft}$ & 0.33 \\
\hline Depth, $\mathrm{ft}$ & 5,500 \\
\hline Pore pressure gradient, $\mathrm{psi} / \mathrm{ft}$ & 0.46 \\
\hline Overburden stress gradient, $\mathrm{psi} / \mathrm{ft}$ & 0.98 \\
\hline Maximum horizontal stress gradient, $\mathrm{psi} / \mathrm{ft}$ & 1.2 \\
\hline Minimum horizontal stress gradient, $\mathrm{psi} / \mathrm{ft}$ & 0.92 \\
\hline Temperature, ${ }^{\circ} \mathrm{F}$ & 122 \\
\hline Total compressibility, $1 / \mathrm{psi}$ & $6 \times 10^{-6}$ \\
\hline Hydraulic coefficient, $\mathrm{m}^{3} . \mathrm{s} / \mathrm{kg}$ & $1.2 \times 10^{-19}$ \\
\hline Chemical osmotic coefficient, $\mathrm{m}^{3} . \mathrm{s} / \mathrm{kg}$ & $8 \times 10^{-16}$ \\
\hline Moisture diffusivity, $\mathrm{m}^{2} / \mathrm{s}$ & $4 \times 10^{-12}$ \\
\hline Biot coefficient (in plane), $\alpha$, dimensionless & 0.9 \\
\hline Biot coefficient (transverse), $\alpha^{\prime}$, dimensionless & 0.85 \\
\hline Poisson's ratio (in plane), $v$, dimensionless & 0.15 \\
\hline Poisson's ratio (in plane), $v^{\prime}$, dimensionless & 0.19 \\
\hline Elastic modulus (in plane), psi & $2.19 \times 10^{6}$ \\
\hline Elastic modulus (transverse), psi & $1.06 \times 10^{6}$ \\
\hline Cohesion of rock at dry condition, psi & 2,000 \\
\hline Angle of internal friction, degree & 30 \\
\hline Shale density, $1 \mathrm{bm} / \mathrm{ft}^{3}$ & 162.3 \\
\hline Porosity, dimensionless & 0.06 \\
\hline Water activity of drilling fluid, dimensionless & 0.9 \\
\hline Water activity of drilling fluid, dimensionless & 0.85 \\
\hline Exposure time, hour & 100 \\
\hline
\end{tabular}

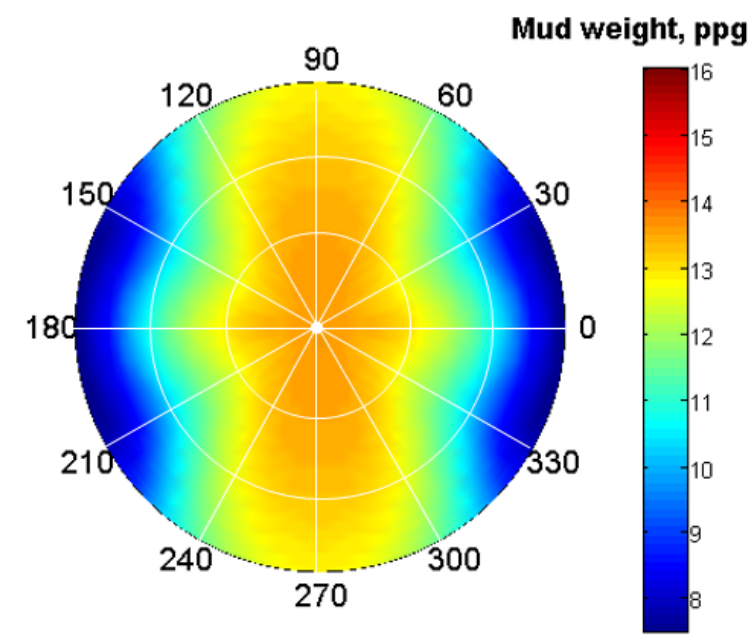

Fig. 6 Polar plot of the lower bound of mud weight when UCS is constant.

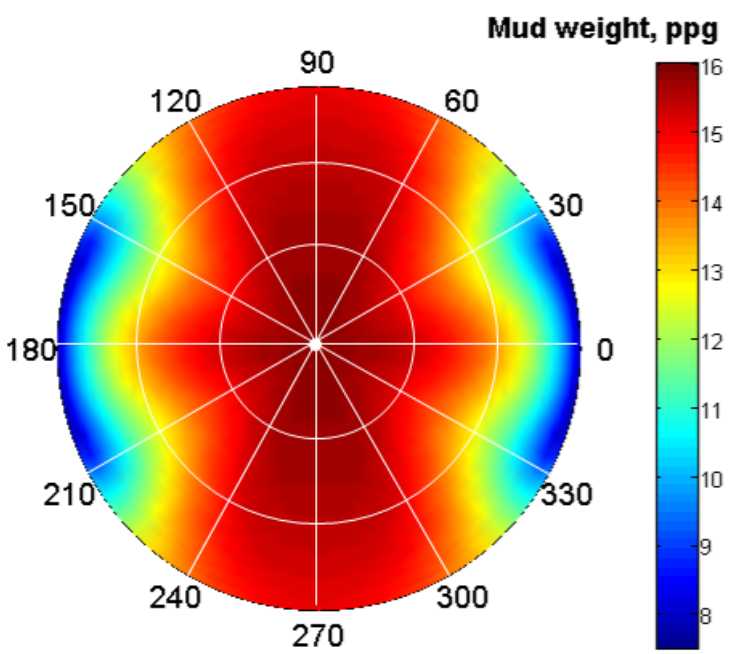

Fig. 7 Polar plot of the lower bound of mud weight when UCS is a function of moisture content.

maximum horizontal stress direction, and deviations from the center show the borehole inclination angle. The advantage of polar plot becomes evident as drilling engineers explore the optimum drilling direction.

The base case examines the stability of the borehole in a transversely isotropic shale formation and neglects the effect of moisture content on the rock strength. Fig. 6 shows a polar plot of the lower critical mud weights for the base case in which the shear failure across the rock matrix is investigated.

The effect of moisture diffusion on the lower bound of mud weights is shown in Fig. 7. It is evident that in strike-slip regime, the least required mud weight occurs 
for horizontal wellbores along the direction of minimum horizontal stress. It is realized that including the effects of moisture diffusion in the model increases the magnitude of the lower bound mud weight but does not change the shape of the plot. Thus, including moisture diffusion phenomenon provides a conservative estimate of the required mud weight.

\section{Conclusions}

Adsorption isotherms of two rock types, Mancos Shale and Catoosa shale, were obtained through laboratory investigation and the results were compared with various data sets in the literature. It is shown that the GAB model can best describe the sorption behavior of the selected shale rocks. It was also found that the adsorption parameter can be introduced as an index to characterize different shale formations. The presented methodology facilitates estimation of compressive strength of shale formations under in-situ conditions.

A diffusion-sorption model is developed to investigate the effect of moisture diffusion on wellbore stability in shale formations. Results of parametric analysis indicate that the sorption parameters of shale have a significant impact on the magnitude of induced osmotic pressure, hence, the magnitude of effective stress. The model is partially coupled with a wellbore stability module which evaluates the state of stress around the borehole of transversely isotropic shale formations. It is found that the collapse pressure strongly depends on the sorption tendency of the given shale. This study integrates both the theoretical and experimental work in order to properly address wellbore instability problems for troublesome shale formation.

\section{Acknowledgments}

The authors acknowledge the financial support of the Tulsa University Center of Research Excellence and Tulsa University Drilling Research Projects.

\section{References}

[1] Okland, D., and Cook, J. M. 1998. "Bedding-Related
Borehole Instability in High-Angle Wells.” (SPE 47285). In SPE/ISRM Rock Mechanics in Petroleum Engineering.

[2] Edwards, S., Matsutsuyu, B., and Willson, S. 2004. "Imaging Unstable Wellbores While Drilling." SPE Drilling \& Completion 19 (4): 236-43.

[3] Mokhtari, M., Bui, B. T., and Tutuncu, A. N. 2014. "Tensile Failure of Shales: Impacts of Layering and Natural Fractures." In SPE Western North American and Rocky Mountain Joint Meeting. Society of Petroleum Engineers.

[4] York, P. L., Prichard, D. M., and Dodson, J. K. 2009. "Eliminating Non-productive Time Associated with Drilling through Trouble Zones." (OTC 20220). In Offshore Technology Conference.

[5] Hamayun, R. 2011. "Remote Workflows Put Digital Resources to Work to Reduce NPT." Drilling Contractor 67 (2).

[6] van Oort, E., Hale, A. H., Mody, F. K., and Roy, S. 1996. "Transport in Shales and the Design of Improved Water-based Shale Drilling Fluids." SPE Drilling \& Completion 11 (03): 137-46.

[7] Labenski, F., and Reid, P. 2003. "Drilling Fluids Approaches for Control of Wellbore Instability in Fractured Formations." (SPE 85304). In SPE/IADC Middle East Drilling Technology Conference and Exhibition. Society of Petroleum Engineers.

[8] Cases, J. M., Bérend, I., François, M., Uriot, J. P., Michot, L. J., and Thomas, F. 1997. "Mechanism of Adsorption and Desorption of Water Vapor by Homoionic Montmorillonite; 3, the $\mathrm{Mg}^{2+}, \mathrm{Ca}^{2+}$, and $\mathrm{Ba}^{3+}$ Exchanged Forms." Clays and Clay Minerals 45 (1): 8-22.

[9] Clark, D. E., and Benaissa, S. 1993. "Aluminum Chemistry Provides Increases Shale Stability with Environmental Acceptability." (SPE 25321) In SPE Asia Pacific Oil and Gas Conference. Society of Petroleum Engineers.

[10] van Oort, E. 2003. "On the Physical and Chemical Stability of Shales." Journal of Petroleum Science and Engineering 38 (3): 213-35.

[11] Sherwood, J. D. 1993. "Biot Poroelasticity of a Chemically Active Shale." Proceedings of the Royal Society of London. Series A: Mathematical and Physical Sciences 440 (1909): 365-77.

[12] Keijzer, T. J. S. 2000. "Chemical Osmosis in Natural Clayey Materials." Vol. 196. Utrecht University.

[13] Revil, A., and Leroy, P. 2004. "Constitutive Equations for Ionic Transport in Porous Shales." Journal of Geophysical Research: Solid Earth (1978-2012) 109 (B3).

[14] Wilson, M. J., and Wilson, L. 2014. "Clay Mineralogy and Shale Instability: An Alternative Conceptual Analysis." Clay Minerals 49 (2): 127-45.

[15] Ewy, R. T., and Stankovich, R. J. 2002. "Shale-Fluid 
Interactions Measured under Simulated Downhole Conditions." In SPE/ISRM Rock Mechanics Conference. Society of Petroleum Engineers.

[16] Sherwood, J. D. 1995. "Ionic Transport in Swelling Shale." Advances in Colloid and Interface Science 61: 51-64.

[17] Lomba, R. F., Chenevert, M. E., and Sharma, M. M. 2000. "The Role of Osmotic Effects in Fluid Flow through Shales." Journal of Petroleum Science and Engineering 25 (1): 25-35.

[18] Yu, M., Chenevert, M. E., and Sharma, M. M. 2003. "Chemical-Mechanical Wellbore Instability Model for Shales: Accounting for Solute Diffusion." Journal of Petroleum Science and Engineering 38 (3): 131-43.

[19] Huang, L., Yu, M., Miska, S. Z., Takach, N. E., and Bloys, J. B. 2012. "Parametric Sensitivity Study of Chemo-Poro-Elastic Wellbore Stability Considering Transversely Isotropic Effects in Shale Formations." In SPE Canadian Unconventional Resources Conference. Society of Petroleum Engineers.

[20] Keenan, A. G., Mooney, R. W., and Wood, L. A. 1951. "The Relation between Exchangeable Ions and Water Adsorption on Kaolinite." The Journal of Physical Chemistry 55 (9): 1462-74.

[21] Chenevert, M. E. 1970. "Shale Alteration by Water Adsorption." Journal of Petroleum Technology 22 (09): 1141-8.

[22] Tien, C. 1994. "Representation, Correlation and Prediction of Single-Component Adsorption Equilibrium Data." In Adsorption calculations and Modeling. Boston: Butterworth-Heinemann, 15-41.

[23] Mooney, R. W., Keenan, A. G., and Wood, L. A. 1952. "Adsorption of Water Vapor by Montmorillonite. I. Heat of Desorption and Application of BET Theory." Journal of the American Chemical Society 74 (6): 1367-71.

[24] Keren, R., and Shainberg, I. 1975. "Water Vapor Isotherms and Heat of Immersion of $\mathrm{Na}$ /Ca-Montmorillonite Systems: I, Homoionic Clay." Clays and Clay Minerals 23 (3): 193-200.

[25] Woodruff, W. F., and Revil, A. 2011. "CEC-Normalized Clay-Water Sorption Isotherm." Water Resources Research 47: 11.

[26] Revil, A., and Lu, N. 2013. "Unified Water Isotherms for Clayey Porous Materials.” Water Resources Research 49 (9): 5685-99.

[27] Chemkhi, S., Zagrouba, F., and Bellagi, A. 2004. "Thermodynamics of Water Sorption in Clay." Desalination 166: 393-9.

[28] Mihoubi, D., and Bellagi, A. 2006. "Thermodynamic Analysis of Sorption Isotherms of Bentonite." The Journal of Chemical Thermodynamics 38 (9): 1105-10.

[29] Newman, A. C. D. 1983. "The Specific Surface of Soils Determined by Water Sorption." Journal of Soil Science
34 (1): 23-32.

[30] Salles, F., Douillard, J. M., Denoyel, R., Bildstein, O., Jullien, M., Beurroies, I., and Van Damme, H. 2009. "Hydration Sequence of Swelling Clays: Evolutions of Specific Surface Area and Hydration Energy." Journal of Colloid and Interface Science 333 (2): 510-22.

[31] Krushin, J. T. 2005. "Quantifying Shale Porosity-A Thermodynamically Based, Predictive Model Which Includes the Effects of Mechanical Compaction, Temperature, Mineralogy, and Chemical Diagenesis." Gulf Coast Assoc. Geo. Soc. Trans. 55: 401-14.

[32] Tandanand, S. 1985. "Moisture Adsorption Rate and Strength Degradation of Illinois Shales." In the 26th US Symposium on Rock Mechanics (USRMS).

[33] Fonseca, C. F. 1998. "Chemical-Mechanical Modeling of Wellbore Instability in Shales." Doctoral dissertation, University of Texas at Austin.

[34] Krushin, J. T. 2013. "A True Shale Compaction Model with Pore Pressure Prediction." In Offshore Technology Conference. doi:10.4043/23954-MS.

[35] Andrade, P. R. D., Lemus, M. R., and Pérez, C. C. E. 2011. "Models of Sorption Isotherms for Food: Uses and Limitations." Vitae 18 (3): 325-33.

[36] Anderson, R. B. 1946. "Modifications of the Brunauer, Emmett and Teller Equation." Journal of the American Chemical Society 68 (4): 686-91.

[37] Foo, K. Y., and Hameed, B. H. 2010. "Insights into the Modeling of Adsorption Isotherm Systems." Chemical Engineering Journal 156 (1): 2-10.

[38] Dokhani, V., Yu, M., and Bloys, B. 2014. "The Effects of Moisture Transport on Wellbore Stability in Shale Formations." In 48th U.S. Rock Mechanics/Geomechanics Symposium. Minneapolis, MN, June 2-4.

[39] Bourgoyne, A. T., Millheim, K. K., Chenevert, M. E., and Young, F. S. 1991. "Drilling Fluids." In Applied Drilling Engineering, SPE Text Book Series, Second Printing, 42-84.

[40] Chenevert, M. E. K., and Osisanya, S. O. 1992. "Shale Swelling at Elevated Temperature and Pressure." In the 33th US Symposium on Rock Mechanics (USRMS). American Rock Mechanics Association.

[41] Ledgerwood III, L. W., and Salisbury, D. P. 1991. "Bit Balling and Wellbore Instability of Downhole Shales." In SPE Annual Technical Conference and Exhibition. Society of Petroleum Engineers.

[42] Aderibigbe, A. A., and Lane, R. H. 2013. "Rock/Fluid Chemistry Impacts on Shale Fracture Behavior." (SPE-164102-MS). In SPE International Symposium on Oilfield Chemistry, Woodland, Texas, 8-10 April 2013.

[43] Colback, P. S. B., and Wiid, B. L. 1965. "The Influence of Moisture Content on the Compressive Strength of Rocks." Proc. Rock Mech. Symposium, Toronto, 65-83. 
[44] Ajalloeian, R., and Lashkaripour, G. R. 2000. "Strength Anisotropies in Mud Rocks." Bulletin of Engineering Geology and the Environment 59 (3): 195-9.

[45] Hsu, S. C., and Nelson, P. P. 2002. "Characterization of Eagle Ford Shale.” Engineering Geology 67 (1): 169-83.

[46] AL-Bazali, T. 2013. "The Impact of Water Content and Ionic Diffusion on the Uniaxial Compressive Strength of Shale." Egyptian Journal of Petroleum 22 (2): 249-60.

[47] Chang, C., Zoback, M. D., and Khaksar, A. 2006. "Empirical Relations between Rock Strength and Physical Properties in Sedimentary Rocks." Journal of Petroleum Science and Engineering 51 (3): 223-37.

[48] Ebrahimi, P., Jaiswai, P., Harimkar, S., and Pucketter, J. 2013. "Mechanical Properties of Mississippian Rocks." In AAPG Mid-Continent Section Meeting, Article \# 41239.

[49] Bostrøm, B., Svanø, G., Horsrud, P., and Askevold, A. 1998. "The Shrinkage Rate of KCl-Exposed Smectitic North Sea Shale Simulated by a Diffusion Model." (SPE 47254). In EUROCK 98. Symposium.

[50] Yew, C. H., Chenevert, M. E., Wang, C. L., and Osisanya, S. O. 1990. "Wellbore Stress Distribution Produced by Moisture Adsorption." SPE Drilling Engineering 5 (4): 311-6.

[51] Huang, L., Yu, M., Miska, S. Z., Takach, N. E., and Bloys, J. B. 2011. "Modeling Chemically Induced Pore Pressure Alterations in Near Wellbore Region of Shale Formations." In SPE Eastern Regional Meeting. Society of Petroleum Engineers.

[52] Dokhani, V. 2014. "The Effects of Chemical Adsorption on Wellbore Stability in Transversely Isotropic Shale Formation.” Ph.D. dissertation, University of Tulsa.
[53] Yew, C. H., and Liu, G. 1992. "Pore Fluid and Wellbore Stabilities." (SPE 22381) In International Meeting on Petroleum Engineering. Society of Petroleum Engineers.

[54] Chen, G. 2001. "A Study of Wellbore Stability in Shales Including Poroelastic, Chemical, and Thermal Effects." Ph.D. dissertation, the University of Texas at Austin.

[55] Rafieepour, S., Jalayeri, H., Ghotbi, C., and Pishvaie, M. R. 2015. "Simulation of Wellbore Stability with Thermo-hydro-chemo-mechanical Coupling in Troublesome Formations: An Example from Ahwaz Oil Field, SW Iran.” Arabian Journal of Geosciences 8 (1): 379-96.

[56] Abousleiman, Y., and Cui, L. 1998. "Poroelastic Solutions in Transversely Isotropic Media for Wellbore and Cylinder." International Journal of Solids and Structures 35 (34): 4905-29.

[57] Nguyen, V., Abousleiman, Y. N., and Hemphill, T. 2009. "Geomechanical Coupled Poromechanics Solutions While Drilling in Naturally Fractured Shale Formations with Field Case Applications." (SPE 123901). In SPE Annual Technical Conference and Exhibition.

[58] Chen, Y., Yu, M., and Takach, N. E. 2015. "Hidden Impact of Mud Loss on Wellbore State of Stresses Disclosed by Thermal-Poro-Elastic Modeling." In 49th U.S. Rock Mechanics/Geomechanics Symposium. American Rock Mechanics Association.

[59] Jaeger, J. C., Cook, N. G., and Zimmerman, R. 2007. Fundamentals of Rock Mechanics. Blackwell Publishing, Malden, MA.

[60] Trefethen, L. N., and Bau III, D. 1997. Numerical Linear Algebra (Vol. 50). Siam. 


\section{Appendix A: Numerical Solution}

Using an implicit finite difference method, the discretized form of Eq. (6) is expressed as:

$$
(M) a_{w_{j-1}}^{n+1}+(N) a_{w_{j}}^{n+1}+(O) a_{w_{j+1}}^{n+1}=-f^{\prime}\left(a_{w_{j}}^{n}\right) a_{w_{j}}^{n}
$$

where the following coefficients are introduced:

$$
\begin{gathered}
M=\frac{D_{w}^{e f f} \Delta t}{\Delta r^{2}}\left[\frac{2}{a_{w_{j}}{ }^{n}+a_{w_{j}-1}{ }^{n}}-\frac{\Delta r}{2\left(r_{w}+j \Delta r\right) a_{w_{j}}{ }^{n}}\right] \\
N=-\frac{2 D_{w}^{e f f} \Delta t}{\Delta r^{2}}\left[\frac{1}{a_{w_{j+1}}^{n}+a_{w_{j}}{ }^{n}}-\frac{1}{a_{w_{j+1}}^{n}+a_{w_{j-1}}{ }^{n}}\right]-f^{\prime}\left(a_{w_{j}}{ }^{n}\right) \\
O=\frac{D_{w}^{e f f} \Delta t}{\Delta r^{2}}\left[\frac{2}{a_{w_{j}}{ }^{n}+a_{w_{j+1}}{ }^{n}}+\frac{\Delta r}{2\left(r_{w}+j \Delta r\right) a_{w_{j}}{ }^{n}}\right]
\end{gathered}
$$

Here, $\Delta t$ and $\Delta r$ are time step-size and space step-size, respectively. Note that $f^{\prime}$ is obtained by differentiating the adsorption model with respect to water activity. For example, by selecting the GAB model, we obtain:

$$
f^{\prime}=\frac{k q_{m}\left(1+\left(k a_{w}\right)^{2}(c-1)\right) c}{\left(\left(k a_{w}-1\right)\left(1+\left(k a_{w}\right)(c-1)\right)\right)^{2}}
$$

Once the initial and boundary conditions are applied, (A-1) can be organized as:

$$
\left[A_{W}\right]\left\{a_{w j}^{n+1}\right\}=\left\{B_{W}\right\}
$$

where $\left[A_{w}\right]$ represents the matrix of the coefficient, and $\left\{B_{w}\right\}$ is the vector of known values and prescribed boundary conditions, all evaluated at the old time step, $n$. Meanwhile, $\left\{a_{w j}{ }^{n+1}\right\}$ is the vector of unknowns to be evaluated at the new time step, $n+1$. Thus, a large set of linear equations is formed, which requires an iterative method to be solved. The numerical solution is pursued using the conjugate gradient method, which is an iterative method suitable for large sparse matrices [60]. A computer code was developed in $\mathrm{C}++$ programming environment to solve the system of equations. Once water activity is obtained in the new time step, we can compute the moisture content at every grid point around the borehole. Similarly, Eq. (11) can be discretized as:

$$
(U) p_{j-1}^{n+1}+(V) p_{j}^{n+1}+(W) p_{j+1}^{n+1}=-p_{j}^{n}-f p_{j}\left(a_{w_{j}}^{n+1}-a_{w_{j}}^{n}\right)
$$

where

$$
\begin{gathered}
U=\frac{K_{I} \Delta t}{\phi c_{t} \Delta r^{2}}\left[1-\frac{\Delta r}{2\left(r_{w}+j \Delta r\right)}\right] \\
V=-1-\frac{2 K_{I} \Delta t}{\phi c_{t} \Delta r^{2}} \\
W=\frac{K_{I} \Delta t}{\phi c_{t} \Delta r^{2}}\left[1+\frac{\Delta r}{2\left(r_{w}+j \Delta r\right)}\right]
\end{gathered}
$$




$$
f p_{j}=\frac{K_{I I} R T}{D_{e f f} c_{t} \phi} f^{\prime}\left(a_{w j}^{n}\right)
$$

After applying the initial and boundary conditions, (A-7) can be rearranged as:

$$
\left[A_{P}\right]\left\{p_{j}^{n+1}\right\}=\left\{B_{P}\right\}
$$

where $\left[A_{P}\right]$ represents the matrix of the coefficient in the pressure equation, and $\left\{B_{P}\right\}$ includes known values over the domain and prescribed boundary condition, all evaluated at old time step $n$. The conjugate gradient method is also used to solve for the unknown pressures at the new time step. The numerical code was indeed verified with an explicit scheme to ensure the correct convergence of the iterative method.

\section{Appendix B: Fluid-Induced Stresses}

Using plain strain assumption, substitution of Eqs. (15) and (16) into the constitutive Eqs. (17-19) yields:

$$
\begin{aligned}
& \sigma_{r r}=M_{11} \frac{\partial u_{r}}{\partial r}+M_{12} \frac{u_{r}}{r}+\alpha p \\
& \sigma_{\theta \theta}=M_{12} \frac{\partial u_{r}}{\partial r}+M_{11} \frac{u_{r}}{r}+\alpha p \\
& \sigma_{z z}=M_{13} \frac{\partial u_{r}}{\partial r}+M_{13} \frac{u_{r}}{r}+\alpha^{\prime} p
\end{aligned}
$$

Then, the above formulations are substituted into the equilibrium equation, i.e. Eq. (14). Since the initial pore pressure throughout the domain is a constant value, it is convenient to express the final relationship in terms of the differential pressure:

$$
\left(\frac{\partial^{2} u_{r}}{\partial r^{2}}+\frac{1}{r} \frac{\partial u_{r}}{\partial r}+\frac{u_{r}}{r}\right)=\frac{-\alpha}{M_{11}} \frac{\partial \Delta p}{\partial r}
$$

After two consecutive integrations of (B-4), the following solution is obtained:

$$
u_{r}=-\frac{\alpha}{M_{11}} \frac{1}{r} \int_{r_{w}}^{r} \Delta p\left(r^{\prime}, t\right) r^{\prime} d r^{\prime}+C_{1} r+\frac{C_{2}}{r}
$$

where $r$ ' is the integration variable to be distinguished from the upper bound of integration. It should be reminded the radial displacement at far field is constrained. To comply with the given condition, $C_{l}$ must be zero. Substituting (B-5) into Eqs. (15) and (16), and then updating (B-1, B-2) yields:

$$
\begin{gathered}
\sigma_{r r}=\frac{\alpha}{M_{11}} \frac{E}{(1+v)} \frac{1}{r^{2}} \int_{r_{w}}^{r} \Delta p\left(r^{\prime}, t\right) r^{\prime} d r^{\prime}-\frac{E}{(1+v)} \frac{C_{2}}{r^{2}} \\
\sigma_{\theta \theta}=\frac{-\alpha}{M_{11}} \frac{E}{(1+v)}\left(\frac{1}{r^{2}} \int_{r_{w}}^{r} \Delta p\left(r^{\prime}, t\right) r^{\prime} d r^{\prime}-\Delta p(r, t)\right)+\frac{E}{(1+v)} \frac{C_{2}}{r^{2}}
\end{gathered}
$$

Since the radial stress at the borehole wall is equal to the mud pressure, the coefficients $C_{2}$ can be determined as:

$$
C_{2}=-\frac{(1+v)}{E} P_{w b} r_{w}^{2}
$$

As a result, the following expressions are obtained: 


$$
\begin{gathered}
\sigma_{r r}=\frac{\alpha}{M_{11}} \frac{E}{(1+v)} \frac{1}{r^{2}} \int_{r_{w}}^{r} \Delta p\left(r^{\prime}, t\right) r^{\prime} d r^{\prime}+P_{w b} \frac{r_{w}{ }^{2}}{r^{2}} \\
\sigma_{\theta \theta}=\frac{-\alpha}{M_{11}} \frac{E}{(1+v)}\left(\frac{1}{r^{2}} \int_{r_{w}}^{r} \Delta p\left(r^{\prime}, t\right) r^{\prime} d r^{\prime}-\Delta p(r, t)\right)-P_{w b} \frac{r_{w}{ }^{2}}{r^{2}}
\end{gathered}
$$

Accordingly, the vertical component of the fluid induced stress can be obtained in a similar manner:

$$
\sigma_{z z}=\left(\frac{\alpha v^{\prime} E^{\prime}}{M_{11}(1+v)}+\alpha^{\prime}\left(1-2 v^{\prime}\right)\right) \Delta p(r, t)+\alpha^{\prime}\left(1-2 v^{\prime}\right) P_{o}
$$

